\title{
The need to use management systems to enhance the competitiveness of the world agrarian and food markets for fruit and vegetable products
}

\author{
Akramov Tokhir Abdirakhmonovich ${ }^{1}$, Imomov Jamshidxon Odilovich ${ }^{2}$, Yusupova \\ Kamola Axmadbekovna ${ }^{3}$ \\ ${ }^{1}$ Doctor of Science at the Tashkent State University of Economics, Tashkent, Republic of \\ Uzbekistan \\ ${ }^{2,3}$ Researcher at the Tashkent State University of Economics, Tashkent, Republic of Uzbekistan
}

Email: akramov_t@umail.uz

\begin{abstract}
This article highlights the ongoing reforms to maximize the role and importance of agriculture in the economy of the Republic of Uzbekistan, its implications, the future development of the sector, the need to improve the competitiveness of fruit and vegetable products, and the need to implement sector management systems. Proposals and recommendations on perspectives of increasing the competitiveness of fruit and vegetable products in the global agrarian and food markets are also given.

Keywords: Strategy of action, agriculture, fruit and vegetable set, quality, security, management systems, ISO, HACCP, GlobalG.A.P., Competitiveness, standard.

\section{INTRODUCTION}

The ongoing reforms in the Republic of Uzbekistan aimed at creating a stable and efficient economy have already shown their results. In particular, following the results of 2018 the gross domestic product of Uzbekistan will make up 407514,5 billion dollars. soums. This positive result has been achieved through systemic economic reforms in sectors and sectors of the economy, particularly in agriculture, including improving the quality and competitiveness of agricultural products on the world market, with an average annual GDP growth rate of 4.5\% over the period 1991-2018. This can be seen by the Successful implementation of investment policy in the modernization, technical and technological renewal of agricultural production, formation and development of dehkan and private farms, and systematic implementation of export-oriented economic reforms are important.

The major part of export-import products in the agricultural sector of the country is occupied by fruit and vegetable products. Uzbekistan has a long standing tradition in the world with its unique taste, richness of vitamins and ecological cleanliness. Demand for such products is growing in the global market. In turn, it is important to introduce new processing techniques and technologies to the country to further strengthen ties with foreign partners to expand the market of agricultural products, especially fruit and vegetable products, and to develop the storage and processing industries. important.

The strategy of actions for further development of the Republic of Uzbekistan approved by the Decree of the President of the Republic of Uzbekistan "On the Strategy of actions for further development of the Republic of Uzbekistan" for 2017-2021. Significant increase in the export potential of the agricultural sector;

- implementation of investment projects for the construction, reconstruction and modernization of existing facilities, equipped with the latest high-tech equipment for deep processing of agricultural products, production of semi-finished products and finished food products, as well as packaging;

- Continuous work on further development of agriculture, further increase of competitiveness of agricultural products on the world agrarian and food markets, defining priority for infrastructure of
\end{abstract}


storage, transportation and sale of agricultural products, provision of agrochemical, financial and other modern market services. of the Earth ${ }^{1}$.

At present the socio-economic development of the countries of the world in its essence differs significantly from previous ones. The main and most important aspect of this is the increasing integration and globalization of national economies. At the same time, these processes will also increase competition in the international arena and strengthen each country's struggle to strengthen its position in the international division of labor. One of the key factors in ensuring the competitiveness of products is the quality $^{2}$. Currently, it is important for most consumers and domestic or foreign partners not only the quality of the products, but also the systematic quality assurance process from the production to the delivery process. Guaranteed implementation of these processes will require the introduction of the Quality Management System (QMS).

\section{ANALYSIS AND RESULTS}

According to the trend of agricultural development, from the first days of independence largescale reforms were launched to develop this sector. Initially, the private sector in the agricultural sector was formed and private landowners, such as peasants and farms, were replaced by state-owned land, that is, peasants and farms. As a result, agricultural production has slowly been shifted to the private sector. As a result of the reforms in the agricultural sector, high economic efficiency is achieved in the sector (Figure 1).

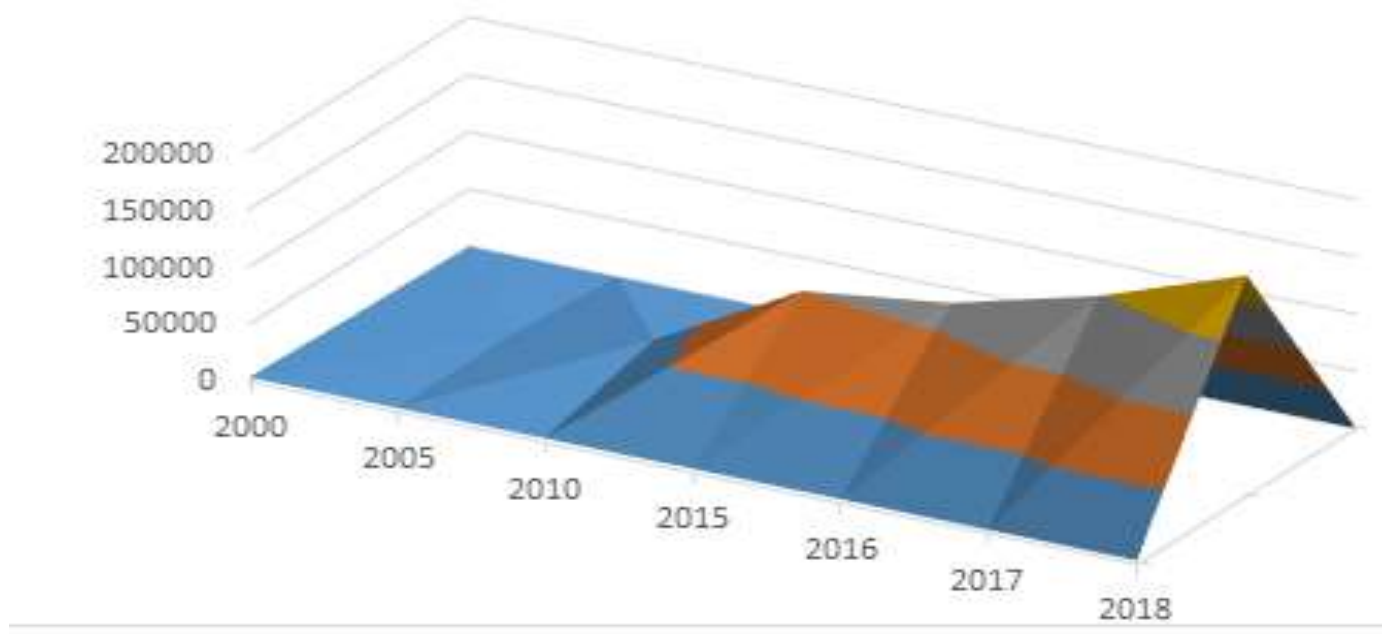

Figure 1. The main indicators of agriculture

Analyzing the statistics, we can see that the area under cultivated crops has declined for the households and for the development of the industrial sector, but there is an increase in agricultural production. Compared to the year of 2000 , the crop area was $88.2 \%$. However, we can see that during this period the volume of agricultural production has increased 130 times in current prices.

Table 2

Volume of Exports of Fruit and Vegetables from Uzbekistan in 2010-2017 ${ }^{3}$

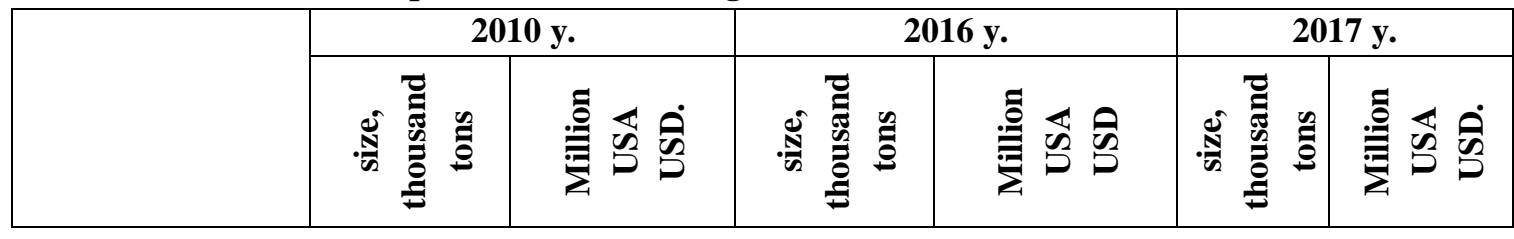

\footnotetext{
${ }^{1}$ Decree of the President of the Republic of Uzbekistan dated February 7, 2017 N UP-4947 "On the Strategy of Action for the Further Development of the Republic of Uzbekistan". // "People's Word" dated February 8, 2017 № 28 (6722).

${ }^{2}$ Sviridova O.I. "Fundamentals of the formation of a quality management system in agricultural enterprises" Vestnik OrelGAU, 2 (53), April 2015.

${ }^{3}$ Data from the State Statistics Committee
} 


\begin{tabular}{|c|c|c|c|c|c|c|}
\hline $\begin{array}{c}\text { Total fruit and } \\
\text { vegetable } \\
\text { products }\end{array}$ & 639,9 & 1114,7 & 796,2 & 554,3 & 831,7 & 592,6 \\
\hline
\end{tabular}

Exports of fruits and vegetables and processed products, which are expected to make up one of the main foreign trade volumes of our country in the near future, will reach US $\$ 708.8$ million by the end of 2017 . USD, or $15.6 \%$ more than in the previous year (Table 1).

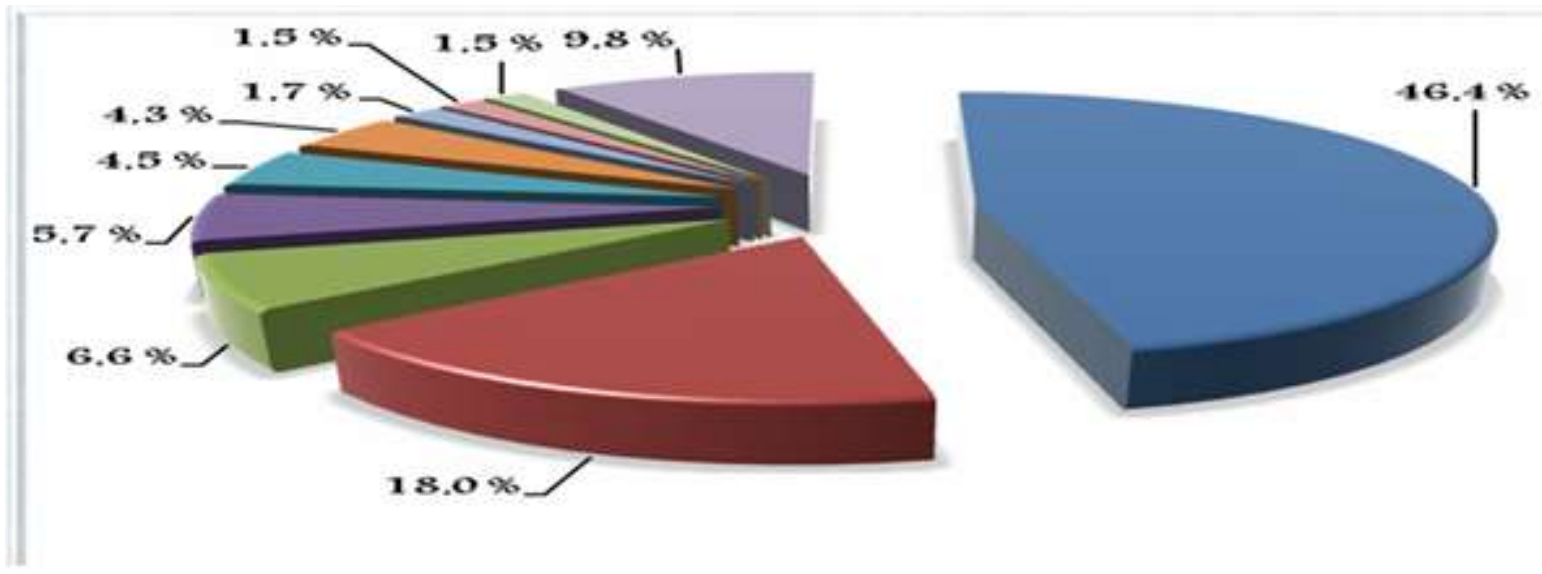

Figure 2. Share of export of fruit and vegetable products and their products by major partner countries, $\%$

The main partners in export of fruits and vegetables in the foreign trade turnover are Kazakhstan (46.4\%), Russia (18.0\%), Afghanistan (6.6\%), China (5.7\%). Turkey (4.5\%) and Kyrgyzstan (4.3\%). Our statistical analysis shows that in 2016, 697 exporters exported to 51 countries while 697 exporters exported to 62 countries in 2017 (Figure 2).

Further development of export of fruit and vegetable products grown in Uzbekistan, expansion of its geographical composition, long-term transportation of fruit and vegetable products through special refrigerated warehouses, refrigerators, packaging and design according to international standards. requires timely resolution of improvement problems.

International experience shows that as a result of competition in the global agrarian and food markets, some countries, integration groups and regional intergovernmental organizations form their own requirements in accordance with international standards for the quality of agricultural products.

In the field of agriculture ISO 9001:20084 (ISO 22006: 2009 "Quality Management Systems Guidelines for the Application of ISO 9001: 2008 to crop production" was developed on the basis of international standard ISO 9000). This standard was developed and approved by the Technical Committee of the International Quality Organization ISO / TC 34 - ISO 22000 - HACCP (Hazard analysis and critical control points) The ISO 22006: 2009 standard is recommended for inclusion in the agricultural production process (elevators, storage warehouses, agricultural cooperatives).

In addition to the international agricultural standards mentioned above, the international standard GAPs - Good Agricultural Practices is also worth noting. This international standard is a set of normative documents on ensuring the quality and safety of agricultural produce. The basic rules set out in it can be applied to different stages of agricultural production. GAP focuses on soil, water, workers and personnel, as well as production and processing components in agricultural production.

Observance of the important elements of the above principles will ensure that enterprises and farms operating in the agricultural sector ensure the safety of products produced on the basis of the quality management system.

\footnotetext{
${ }^{4}$ It is a normative document on the application of ISO 9001: 2008 requirements in the field of crop production.
} 
Although there are some differences in the principles of introducing the standards proposed by these organizations in the field of agricultural production, the GAP standard is certified by a third party, such as the ISO 9001 standard, by an international standard organization.

\section{CONCLUSION AND RECOMMENDATIONS}

Fruit and vegetable products grown in Uzbekistan are very rich in their selection, unique varieties, unique quality, priceless consumption, inimitable taste and aroma, from early spring to late autumn, even in winter, as well as processing and drying. with its delivery to markets at any time of the year is important in the domestic and global markets.

Ensure guaranteed quality and safety at every stage of the chain, including the development of the GAP standard and internationally recognized GlobalG.A.P through management systems based standards. Compliance with the standards will be an important tool in increasing the competitiveness of the Uzbek fruit and vegetable products in the global agrarian and food markets.

\section{REFERENCES}

1. Decree of the President of the Republic of Uzbekistan dated February 7, 2017 N UP-4947 "On the Strategy of Action for the Further Development of the Republic of Uzbekistan". // "People's Word" dated February 8, 2017 № 28 (6722).

2. Sviridova O.I. "Fundamentals of the formation of a quality management system in agricultural enterprises" Vestnik OrelGAU, 2 (53), April 2015.

3. It is a normative document on the application of ISO 9001: 2008 requirements in the field of crop production. 